\title{
A INFLUÊNCIA DA CRISE NA ESCOLHA PELO CONSUMIDOR ENTRE AGÊNCIAS DE VIAGENS OU OPERADORES ON-LINE
}

\author{
THE INFLUENCE OF ECONOMIC CRISIS ON CONSUMER CHOICE BETWEEN TRAVEL AGENCIES \\ AND ONLINE OPERATORS
}

\section{LA INFLUENCIA DE LA CRISIS EN LA ELECCIÓN DEL CONSUMIDOR ENTRE AGENCIAS DE VIAJES U OPERADORES ON-LINE}

\author{
Laurentina Maria da Cruz Vareiro \\ Prof. Adjunta na ESG do Instituto Politécnico do Cávado e do Ave \\ Diretora do Mestrado em Gestão do Turismo \\ Doutora em Economia pela Universidade do Minho \\ Ivareiro@ipca.pt
}

\author{
Teresa Cláudia de Sousa Pinheiro \\ Mestre em Gestão das Organizações - Instituto Politécnico do Cávado e do Ave \\ claudia.pinheiro@topatlantico.com
}

Data de Submissão: 16/08/2016

Data de Aprovação: 30/03/2017

\begin{abstract}
RESUMO: A crise que tem abalado as economias nos últimos anos despoletou nas pessoas novas formas de entendimento do seu quotidiano. Assiste-se ao surgimento de uma nova readaptação nas rotinas e de maneiras de estar na vida. Verifica-se, assim, o nascer de uma nova consciencialização de escolha nos hábitos diários. Esta nova percepção também se reflete em situações especiais da vida das pessoas, como é o caso da escolha das férias que, para muitas, é a despesa mais avultada do ano: quando, como e quanto podem despender para usufruir de uma semana de férias com a família. A metodologia utilizada neste estudo foi de caráter quantitativo, com base num questionário aplicado a estudantes em várias instituições de ensino superior em Portugal (pós-graduações e mestrados), tendo sido obtidos 412 inquéritos válidos. Tomando o caso dos estudantes, e através da implementação de um inquérito acerca da escolha do fornecedor turístico, pretende-se verificar em que medida a crise influencia a procura das pessoas pelas agências de viagens ou pelos serviços on-line. Este estudo procura, igualmente, perceber as diferenças no comportamento dos consumidores que recorrem, ou não, à Web quando pretendem viajar, quais as motivações pela procura de fornecedores on-line e respectiva aquisição de serviços e produtos turísticos, quais os tipos de produtos, quais as motivações pela procura de agências de viagens e correspondente grau de satisfação e lealdade. O estudo concluiu que, de forma geral, a crise econômica influenciou a escolha do consumidor por fornecedores on-line em detrimento das agências de viagens tradicionais. Verificaram-se, igualmente, diferenças nas motivações e nas caraterísticas mais valorizadas, consoante a procura de fornecedores on-line ou tradicionais.
\end{abstract}

PALAVRAS-CHAVE: Agências de Viagens, Crise, Serviços On-line.

\begin{abstract}
The global financial crisis in recent years has triggered people to re-evaluate their perception of their daily lives. We are witnessing the emergence of new rehabilitation routines and ways of living. It is thus the birth of a new awareness of choice in daily habits. This new perception also reflects on special occasions and times in people's lives, such as the choice of being able to take a vacation, which for many is the largest expenditure of the year. When and how much they can spend to enjoy a week of vacation with family. The methodology used in this study was quantitative, based on a questionnaire applied to students in several higher education institutions in Portugal (post-graduate and master's degrees). 412 valid surveys were obtained. Taking the case of the students, and by implementing a survey about the choice of tourist suppliers, it intends to examine to what extent the crisis affects the demand of people through travel agencies or through online services. This study also seeks to understand the differences in the behaviour of consumers who use, or do not use the web when they intend to travel; the motivations when searching for travel websites, tourism products and suppliers; the types of products; and motivations for choosing travel agencies and corresponding consumer satisfaction and loyalty. The study concluded that, in general, the economic crisis has influenced the choice
\end{abstract}


ISSN: 1983-7151

of the consumer by online suppliers. There were also differences in the motivations and characteristics most valued, depending on the demand of online or traditional suppliers.

KEYWORDS: Travel Agencies, Crisis, Online Services.

RESUMEN: La crisis que ha afectado las economías en los últimos años disparó en las personas nuevas formas de entender su vida cotidiana. Asistimos al surgimiento de una nueva readaptación de las rutinas y de las maneras de estar en la vida. Se observa, así, el nacimiento de una nueva concienciación de las elecciones en los hábitos diarios. Esta nueva percepción también se refleja en situaciones especiales de la vida de las personas, como es el caso de la elección de las vacaciones, que para mucha gente es el gasto más grande del año: cuándo, cómo y cuánto pueden gastar para disfrutar una semana de vacaciones con la familia. La metodología que se utilizó en este estudio fue de carácter cuantitativo, con base en un cuestionario aplicado a estudiantes en diversas instituciones de enseñanza superior en Portugal (posgrados y maestrías), habiéndose obtenido 412 resultados válidos. Tomando el caso de los estudiantes, y a través de la implementación de un cuestionario acerca de la elección del proveedor turístico, se intentó verificar en qué medida la crisis ejerce influencia sobre la búsqueda de las personas de las agencias de viajes o de los servicios on-line. Este estudio también procura percibir las diferencias en el comportamiento de los consumidores que recurren o no a la Web cuando quieren viajar, cuáles son las motivaciones de la búsqueda de proveedores on-line y la respectiva adquisición de servicios y productos turísticos, cuáles los tipos de productos, cuáles las motivaciones de la búsqueda de agencias de viajes y el correspondiente grado de satisfacción y lealtad. El estudio concluyó que, de modo general, la crisis económica influenció la elección del consumidor de proveedores on-line en perjuicio de las agencias de viajes tradicionales. También se observaron diferencias en las motivaciones y en las características más valorizadas, en consonancia con la elección de proveedores on-line o tradicionales.

PALABRAS CLAVE: Agencias de Viajes; Crisis; Servicios On-line.

INTRODUÇÃO

revolução da informação redefiniu a sociedade global empurrando
o mundo para uma economia baseada na informação. O advento
da Web faculta a oportunidade sem precedentes de flexibilização, colaboração e rapidez de consultas, pesquisas, compras, vendas, etc., servindo a todos os que nela navegam. É, assim, a plataforma perfeita para a indústria do turismo e lazer, pois possibilita a informação dos seus produtos aos consumidores de todo o mundo, de uma forma direta, minimizando custos, e de carácter eficiente (Werthner, 1999). Muitos autores defendem que o turismo deve ser visto como uma indústria intensiva (Poon, 1993; Schertler, 1995; Sheldon, 1997; Inkpen, 1998). Por exemplo, Schertler (1995) define turismo como um negócio de informação, pois para que o turismo, como indústria de serviços, suporte a sua eficaz atuação no mercado, a informação é o parâmetro de maior importância. Surge a globalização como consequência da revolução da informação.

Deste modo, a introdução das novas tecnologias na indústria turística veio proporcionar novos hábitos e comportamentos de compra, influenciados ou não 
por alguma motivação específica. No caso concreto das agências de viagem, os avanços tecnológicos conduzem ao desvio do consumidor destas para o acesso imediato à pesquisa e consulta de informação diretamente nas plataformas interativas dos fornecedores. Os horários dos voos, as respetivas ligações, a disponibilidade dos hotéis, as melhores tarifas, os pacotes promocionais e na maior parte dos casos efetuar a própria reserva são proporcionados através destas plataformas (Buhalis e Licata, 2002; Buhalis, 2008).

O turismo é especialmente vulnerável à incerteza e à instabilidade económica, dado que a maioria das viagens envolvem despesas arbitrárias. Em tempos económicos difíceis, nomeadamente, face a pesadas medidas impostas pelo período de austeridade vivido em Portugal (início da intervenção da Troika em 2011), com cortes nos salários e subsídios de férias, subida do IVA para 23\%, congelamento do investimento público, redução no número de trabalhadores contratados na Função Pública, cortes no Abono de Família e Rendimento Social de Inserção (Martins, 2015), seria natural que as despesas relativas às viagens turísticas se reduzissem, bem como as distâncias a percorrer mais curtas e em menos tempo. Por conseguinte, as companhias aéreas, os hotéis e as agências de viagens também têm que se adaptar a esta nova realidade.

No âmbito deste trabalho, e para determinar se a atual crise económica influenciou a escolha do consumidor entre agências de viagens e operadores on-line, bem como aferir sobre as motivações pela procura de uns ou outros (agências de viagens e operadores on-line), foi implementado um inquérito a estudantes do ensino superior em várias instituições de ensino em Portugal. Todos os inquiridos são adultos e utilizam ferramentas Web no seu dia a dia, muito embora as experiências e opiniões divirjam relativamente à escolha do fornecedor turístico.

O questionário foi elaborado em formato papel, de auto resposta, sendo na sua maioria composto por perguntas fechadas. Duas questões, com uma escala de Likert de 5 pontos, foram introduzidas para medir a opinião dos inquiridos acerca de determinadas características relacionadas com a motivação e prestação dos operadores de serviços turísticos on-line, assim como das agências de viagens tradicionais. O tratamento estatístico dos dados foi realizado no programa Statistical Package for the Social Sciences (SPSS v. 18). 
Mantendo presentes os propósitos enunciados, na primeira secção deste artigo faz-se uma sucinta revisão de literatura sobre o comportamento de consulta e compra turística on-line e seus efeitos sobre as agências de viagem. $\mathrm{Na}$ secção seguinte, aborda-se a questão da eficácia do atual modelo de negócios das agências de viagens. Na terceira secção descrevem-se a metodologia adotada na investigação e os principais resultados obtidos. O artigo finaliza com algumas conclusões.

\section{O COMPORTAMENTO DE CONSULTA E COMPRA TURÍSTICA ON-LINE}

Foram já efetuados vários estudos sobre o comportamento de consulta e compra turística on-line, por autores como Nie e Erbring (2000), Ahuja, Gupta e Raman (2003); Law, Leung e Wong (2004); Bennett e Lai (2005); Heung e Zhu (2005); Gallarza e Sauraa (2006); Karami (2006); Lin (2006); Xianyun Gao (2013); Marsilio e Vianna (2014) entre outros.

Law, Leung e Wong (2004); Bennett e Lai (2005) e Heung e Zhu (2005) centraram a preocupação das suas investigações no impacto da internet nas agências de viagens. Para Law, Leung e Wong (2004), o facto da internet permitir facilmente aos consumidores a consulta e compra de produtos e serviços turísticos compromete o futuro das agências de viagens tradicionais. Do mesmo modo, Holloway, Davidson e Humphreys (2009) consideram que a implementação da internet e da tecnologia moderna constituem a maior ameaça, desde o início de 2000, para as agências de viagens tradicionais.

Confiança e credibilidade, flexibilidade e comodidade, relacionamento e aconselhamento, intermediação e desintermediação foram aspetos analisados por Law, Leung e Wong (2004). Estes autores concluíram que as agências de viagens têm melhor performance do que os fornecedores on-line no que respeita à prestação de serviço personalizado. Na mesma linha de investigação, Xianyun Gao (2013) conclui que as agências de viagens tradicionais apresentam vantagens na oportunidade de interação física, fornecimento de produtos e serviços à medida que proporcionam confiança e segurança. Rensburg (2014) defende que os serviços prestados pelas agências de viagens são ainda 
relevantes e valiosos, em resultado do serviço personalizado, da experiência, conhecimento e habilidades dos seus agentes. Por outro lado, o mesmo autor realça a segurança como um aspeto a considerar, pois refere que, apesar dos muitos avanços tecnológicos, muitos viajantes ainda consideram a ideia de viajar assustador e a internet como intimidante.

Na investigação efetuada por Heung e Zhu (2005), foram avaliados critérios como a capacidade interativa, satisfação do cliente, qualidade do serviço, facilidade de estimativa da viagem, imagem da agência de viagens e características do serviço. Analisaram os dados obtidos, comparando-os por grupos de idade, género, habilitações literárias, estado civil e nível de rendimentos, com o objetivo de determinar se existiam diferenças significativas entre os mesmos.

Nie e Erbring (2000) avaliaram as diferenças entre os consumidores quando utilizam a internet para pesquisa de produtos turísticos, para a consulta de informação turística e para a compra de produtos turísticos. Ahuja, Gupta e Raman (2003) investigaram o comportamento de compra on-line, com o objetivo de verificar a existência de diferenças na motivação e na atitude por parte do consumidor quando analisados por categorias demográficas. Nesta investigação, Ahuja, Gupta e Raman (2003) consideraram as motivações de compra on-line das populações estudante e não estudante. Reuniram dados quantitativos de dois grupos distintos: estudantes $(n=190,84,6 \%$ dos quais a tempo inteiro no ensino superior), que são considerados experientes e pouco incomodados com perda de privacidade, e não estudantes ( $n=75,78,9 \%$ dos quais trabalham em quadros superiores), que devem exigir algum conforto na utilização da internet e que se preocupam com a sua privacidade. O estudo revelou que, para ambas as populações, comodidade, preço e poupança de tempo são as motivações que apresentam maiores percentagens.

Heung e Zhu (2005), no estudo realizado acerca do impacto da internet nas agências de viagens em Shangai, avaliaram alguns critérios de motivação para a escolha deste fornecedor turístico. Na China, assim como em Portugal, as agências de viagens são pequenas, com recursos limitados, pouco organizadas e com políticas de gestão deficientes. Ambicionam abranger todos os segmentos de mercado, vendendo os seus produtos e serviços aos mesmos clientes, adotando estratégias idênticas, em vez de direcionarem os seus produtos a segmentos 
ISSN: 1983-7151

específicos. Contudo, como defende Rensburg (2014), as agências de viagens tradicionais devem servir segmentos diferenciados com propostas de valor relevantes, resultantes do conhecimento especializado de produtos turísticos mais complexos, serviço personalizado e aconselhamento pessoal, reservas eficientes, melhores preços, promoções ou reservas exclusivas, mais opções de condições de pagamento, entre outros, e excelente qualidade de serviço.

Gallarza e Sauraa (2006) realizaram um estudo sobre o valor percebido, satisfação e lealdade dos estudantes universitários e a organização das suas viagens. A escolha desta população prendeu-se com o facto de os alunos realizarem, de alguma forma, viagens todos os anos, por serem turistas que desfrutam de férias longas e periódicas, porque atuam como um segmento lucrativo no mercado turístico de lazer e consomem produtos turísticos específicos. Acresce que, em alguns casos, especialmente quando viajam ao estrangeiro, existe um entendimento intercultural entre turistas e anfitriões que possibilita uma experiência turística mais enriquecedora.

\section{A EFICÁCIA DO ATUAL MODELO DE NEGÓCIOS DAS AGÊNCIAS DE VIAGENS}

As novas tecnologias relacionadas à internet alteraram dramaticamente os custos de transação e comunicação, suscitando desafios e oportunidades para o sector empresarial relativamente a questões de natureza e valor de intermediação. A tecnologia de informação é um fator preponderante na determinação do futuro da indústria turística, influenciando, entre outras coisas, a estrutura geral dos canais de distribuição. A tecnologia pode originar novas formas de concorrência, como os serviços de informação e reservas on-line, que permitem ao cliente a marcação de viagens a partir de sua casa. Encontra-se, assim, uma desramificação dos canais distribuidores possibilitando a concorrência tanto do fornecedor como do próprio cliente (Bédard, 2002; Buhalis e O'Connor, 2005; Lawton e Weaver (2009); Elhaj (2012); Standing, TangTaye e Boyer, 2014; Sarquis, Pizzinato, Giuliani e Pontes, 2015).

Hoje são percebidas duas grandes ameaças: a desintermediação das agências retalhistas pelos principais fornecedores e o surgimento de novos intermediários 
virtuais. O potencial de mudanças estruturais no sector das viagens destaca a necessidade de as agências de viagens poderem ativamente escolher os modelos de negócio que podem melhor suportar uma linha estratégica eficaz (Dencker, 2001). A diminuição de custos ocasionada pela evolução tecnológica põe em causa a sustentabilidade de muitos modelos existentes. De acordo com Gilbert e Gao (2005), o fracasso de muitas agências de viagens deve-se ao facto de não conseguirem lidar com a tolerância, a experiência e as emoções do cliente. Um outro fator apontado para este fracasso é a circunstância das agências de viagens tradicionais não estarem a inovar com a intensidade necessária, nem a explorar suficientemente as potencialidades da internet (Barros, 2005, citado por Sarquis et al., 2015).

Num mercado vasto e fragmentado, que enfrenta rápidas mudanças, existe inevitavelmente um ambiente de incerteza no modelo de negócio adotado. As agências de viagens ocupam uma posição singular na indústria turística, caracterizada pela mútua dependência dos seus fornecedores e dos seus clientes. Os fornecedores dependem dos agentes para receber e enviar pagamentos, respeitando as regras estabelecidas. As agências confiam aos fornecedores o cálculo das suas comissões, bem como o fornecimento de informação precisa e atualizada acerca das tarifas acordadas. Por sua vez, os clientes acreditam que os agentes de viagens lhes fornecem serviços com boa relação custo/ eficiência, assim como toda a informação detalhada. De facto, de acordo com Lawson e Weaver (2009), os agentes de viagens tradicionais são muito mais eficientes e apresentam uma melhor relação qualidade-preço na organização de experiências de viagem mais complexas.

Agente de quem? Quem vem primeiro, o fornecedor ou o cliente? O agente de viagens vê-se confrontado diariamente com dois gigantes do seu negócio, os fornecedores e os clientes. Os fornecedores turísticos, como as companhias aéreas, obrigam o agente de viagens a assinar um documento que lhe confere o título de representante oficial, responsabilizando-o, por conseguinte, pela aceitação, respeito e cumprimento das condições e das regras impostas pela companhia aérea, assumindo obrigação principal para com o fornecedor. Como intermediário, a agência de viagens também é responsável pelos serviços fornecidos aos seus clientes, pois estes são a razão de ser do negócio. Sem 
clientes, não há negócio! Neste ambiente, é natural que as agências alinhem os seus interesses de acordo com os interesses dos seus clientes (Dunfee e Black, 1996; Barnett e Standing, 2001).

A própria cadeia de distribuição turística está sobre pressão! Companhias aéreas, hotéis e operadores turísticos começaram a vender diretamente aos consumidores. Esta desintermediação já é considerada uma forte ameaça que tem de ser vencida num futuro próximo. Apesar de serem reais estas ameaças, o crescimento massivo da internet e da cada vez mais popular World Wide Web criou oportunidades de negócio para todos os sectores da indústria turística, possibilitando a interação direta com o consumidor (Buhalis, 1998, 2000; O'Connor, 1999; Richer e O'Neill-Dunne, 1999). Contudo, como referem Marsilio e Vianna (2014), será sempre possível argumentar que determinados clientes continuam a preferir o contacto humano para organizar e comprar as duas viagens.

A credibilidade e a ética profissional são elementos chave para o sucesso das agências de viagens. O profissionalismo, o comprometimento e a competência do agente de viagens são imprescindíveis para a qualidade dos serviços prestados. A percepção comum de que qualquer pessoa pode ser agente de viagens, com o mínimo de investimento e formação, será refletida negativamente na imagem profissional da indústria turística (Dunfee e Black, 1996; Lawson e Weaver, 2009; Flores, Cavalcante e Raye, 2012). De facto, a escolha destes profissionais deve ser cuidada, pois eles agregam valor ao serviço. Como referem Flores, Cavalcante e Raye (2012, p. 330), "o novo posicionamento comercial por parte dos agentes de viagens, transforma-os nos atuais consultores de viagens, que possuem como função auxiliar os clientes na escolha de destinos e fornecer soluções para problemas que estes venham a ter". A nova postura estratégica deve estruturar-se de acordo com alguns requisitos, como a qualidade dos serviços prestados, a formação do profissional de turismo, o desenvolvimento de uma cultura voltada para o mercado e dimensão empresarial. Melhorar continuamente a estrutura de qualificação dos trabalhadores, proporcionando formação de alta qualidade e defendendo a aprendizagem ao longo da vida, estimulando a inovação e incentivando o aumento do nível de tecnologias de informação ao nível da promoção e distribuição de serviços e produtos da 
agência, permitirão às agências de viagens tradicionais manter uma vantagem competitiva para fazer face aos desafios constantes (Vučetić, 2012).

METODOLOGIA

Este estudo procura perceber as diferenças no comportamento dos consumidores que recorrem, ou não, à Web quando pretendem viajar, quais as motivações pela procura de fornecedores on-line e respectiva aquisição de serviços e produtos turísticos, quais os tipos de produtos. Procura, igualmente, perceber quais as motivações pela procura de agências de viagens e correspondente grau de satisfação e lealdade e se a crise influenciou, de alguma forma, a escolha do fornecedor turístico. Foi implementado um inquérito a alunos do ensino superior, entre outubro e novembro de 2011, a turmas de licenciatura, pós-graduação e mestrado de 10 instituições portuguesas de ensino superior público.

A escolha desta população recai precisamente pelo facto de se tratar de uma amostra bastante coerente, isto é, de pessoas adultas, com níveis superiores de escolaridade e por utilizarem ferramentas Web no seu dia a dia. Nie e Erbring (2000) sugerem que $52 \%$ dos consumidores utilizam a internet para pesquisa de produtos turísticos; $42 \%$, para consulta de informação turística; e 24\%, para comprarem produtos turísticos. Considerou-se igualmente pertinente analisar os dados, comparando os resultados entre as variáveis sociodemográficas, nomeadamente entre os grupos de idade, estado civil e nível de rendimentos. Desta forma, as hipóteses de investigação estão descritas na Tabela 1.

Tabela 1. Hipóteses de investigação relacionadas com a escolha do fornecedor turístico

\begin{tabular}{|c|c|}
\hline \multicolumn{2}{|c|}{ Tipo de relação esperado } \\
\hline $\begin{array}{c}\text { Pesquisa e compra de } \\
\text { produtos turísticos } \\
\text { on-line }\end{array}$ & $\begin{array}{c}\text { Hipótese H1 Existem diferenças significativas entre as faixas } \\
\text { etárias na pesquisa de destinos e produtos turísticos on-line; } \\
\text { Hipótese H2 Existem diferenças significativas entre as faixas } \\
\text { etárias no comportamento de compras on-line; } \\
\text { Hipótese H3 Existem diferenças significativas por género no } \\
\text { comportamento de compra on-line; }\end{array}$ \\
$\begin{array}{c}\text { Motivações } \\
\text { pela procura de } \\
\text { fornecedores turísticos } \\
\text { on-line }\end{array}$ & $\begin{array}{c}\text { Hipótese H4 Existem diferenças significativas entre as faixas } \\
\text { etárias nas motivações da procura de fornecedores turísticos } \\
\text { on-line; } \\
\text { Hipótese H5 Existem diferenças significativas entre os níveis } \\
\text { de rendimento nas motivaços da procura de fornecedores } \\
\text { turísticos on-line; }\end{array}$ \\
\hline
\end{tabular}




\begin{tabular}{|c|c|}
\hline $\begin{array}{l}\text { Motivações pela } \\
\text { procura de agências de } \\
\text { viagens }\end{array}$ & $\begin{array}{l}\text { Hipótese H6 Existem diferenças significativas entre as faixas } \\
\text { etárias nas motivações da procura de agências; } \\
\text { Hipótese H7 Existem diferenças significativas entre os níveis } \\
\text { de rendimento nas motivações da procura de agências; }\end{array}$ \\
\hline $\begin{array}{c}\text { A influência da crise na } \\
\text { escolha do fornecedor } \\
\text { turístico }\end{array}$ & $\begin{array}{l}\text { Hipótese H8 Existem diferenças significativas entre as faixas } \\
\text { etárias no que diz respeito à influência da crise económica na } \\
\text { escolha pelo fornecedor on-line; } \\
\text { Hipótese H9 Existem diferenças significativas entre os níveis } \\
\text { de rendimento no que diz respeito à influência da crise } \\
\text { económica na escolha pelo fornecedor on-line; } \\
\text { Hipótese H10 Existem diferenças significativas entre o estado } \\
\text { civil no que diz respeito à influência da crise económica na } \\
\text { escolha pelo fornecedor on-line. }\end{array}$ \\
\hline
\end{tabular}

Fonte: Elaboração própria.

O inquérito construído divide-se em três partes: a primeira relacionada com os operadores on-line; a segunda, com as agências de viagens; e a terceira, com dados sociodemográficos. O estudo ambiciona encontrar resposta para questões como: com que frequência os consumidores adquirem serviços pela internet, que tipo de serviços, respetivo grau de satisfação e lealdade, quais as motivações que levam os consumidores a recorrer aos operadores online, se a atual crise económica influenciou de alguma forma esta escolha, se houve comparação destes serviços com alguma agência de viagens, quais as motivações que levam os consumidores a optar pelos serviços prestados pela agência de viagens, o grau de satisfação e lealdade e, por último, a resposta a questões de ordem sociodemográfica: idade, sexo, estado civil, rendimentos e grau de escolaridade.

O tratamento estatístico dos dados foi realizado em SPSS (v. 18). Recorreuse a métodos de análise estatística univariada, nomeadamente, tabelas de frequência, cálculos de média e desvio-padrão, assim como métodos de análise estatística bivariada, como teste do Qui-Quadrado $\left(X^{2}\right)$, o teste $t$ para duas amostras independentes, o teste Kruskall-Wallis quando existiam mais do que dois grupos. $\mathrm{O}$ teste do $\mathrm{X}^{2}$ foi utilizado para testar se dois ou mais grupos independentes (de acordo com as características sociodemográficas) diferiam relativamente à consulta e à compra de produtos turísticos on-line; à consulta e à compra de produtos turísticos nas agências de viagens e à influência da crise na escolha do fornecedor turístico. A análise da existência de diferenças estaticamente significativas nas motivações de procura de fornecedores 
turísticos on-line e nas motivações de procura de fornecedores turísticos entre os grupos (de acordo com características sociodemográficas) foi realizada utilizando o teste $t$, quando se tinham dois grupos, e o teste de Kruskall-Wallis, quando existiam mais do que dois grupos. O teste não paramétrico KruskallWallis foi utilizado em vez da ANOVA, uma vez que os pressupostos para aplicar este teste não se verificaram.

\section{RESULTADOS E DISCUSSÃO}

\section{PERFIL DOS INQUIRIDOS}

Foram obtidos 412 inquéritos válidos, dos quais se conseguiu apurar que 48,9\% têm até 24 anos, 31,8\% têm entre 25 e 34 anos, 12,7\% têm entre 35 e 44 anos e apenas 6,6\% têm mais de 45 anos. Deste universo, 69,9\% são de sexo feminino e $30,1 \%$, de sexo masculino. No que respeita a habilitações literárias, 5,7\% possuem nível secundário, 68,7\% detêm licenciatura e 25,6\% possuem pós-graduação, mestrado ou doutoramento. Quanto ao estado civil, 75,5\% são solteiros, $22,2 \%$ são casados ou em união de facto e $2,3 \%$ são divorciados. Relativamente ao nível de rendimentos, $13,4 \%$ auferem mais de $2.500 €$ mensais, $41,2 \%$ obtêm entre $1.001 €$ e $2.500 €, 35,4 \%$ recebem entre $501 €$ e $1.000 €$, apenas $10 \%$ auferem até $500 €$.

Tabela 2. Dados sociodemográficos dos inquiridos

\section{Idades}

Até 24 anos

Entre 25 e 34 anos

Entre 35 e 44 anos

Mais de 45 anos

\section{Sexo}

Masculino

Feminino

Habilitações Literárias

Ensino Secundário

Licenciatura

Pós-graduação, Mestrado

\section{Estado Civil}

Solteiro

Casado/União de Facto
$\mathbf{N}$

192

125

50

26

118

274

23

276

103
$\%$

48,9

31,8

12,7

6,6

30,1

69,9

68,7

25,6

75,5

22,2 


\section{Rendimento Médio Mensal}

Líquido

Até $500 €$

Entre $501 €$ e $1.000 €$

Entre $1.001 €$ e $2.500 €$

Mais $2.500 €$
36

127

148

48
10

35,4

41,2

13,4

Fonte: Elaboração própria

Nota: N - Casos Válidos

\section{PESQUISA E COMPRA DE PRODUTOS TURÍSTICOS ON-LINE}

Para a análise da hipótese $\mathbf{H 1}$ (Tabela 3), utilizou-se o teste do $X^{2}$ para testar grupos independentes.

Tabela 3. Pesquisa de destinos e produtos turísticos on-line por grupos de idade

\begin{tabular}{|c|c|c|c|c|c|c|}
\hline \multirow{3}{*}{ Idades } & \multicolumn{4}{|c|}{$\begin{array}{l}\text { Pesquisa de destinos e produtos turísticos } \\
\text { on-line }\end{array}$} & \multirow{3}{*}{$\mathbf{X}^{2}$} & \multirow{3}{*}{ Sig. } \\
\hline & \multicolumn{2}{|c|}{ Sim } & \multicolumn{2}{|c|}{ Não } & & \\
\hline & $\mathbf{N}$ & $\%$ & $\mathbf{N}$ & $\%$ & & \\
\hline Até 24 anos & 170 & 88,5 & 22 & 11,5 & \multirow{4}{*}{7,370} & \multirow{4}{*}{061} \\
\hline Entre 25 e 34 anos & 121 & 96,8 & 4 & 3,2 & & \\
\hline Entre 35 e 44 anos & 44 & 88,0 & 6 & 12,0 & & \\
\hline Mais de 45 anos & 23 & 88,5 & 3 & 11,5 & & \\
\hline
\end{tabular}

Fonte: Elaboração própria.

O resultado obtido permitiu concluir que os inquiridos com idades entre os 25 e 34 anos pesquisam mais destinos e produtos turísticos pela internet do que os restantes grupos de idades, apresentando uma percentagem de 96,8\%. Contudo, sendo o $p$-value $=0,061>\alpha=0,05$, não se rejeita a hipótese de que a pesquisa de destinos on-line é idêntica nos quatro grupos de idade. Por outras palavras, a pesquisa de destinos on-line é independente da idade.

Ahuja, Gupta e Raman (2003) avaliaram quais os produtos que estavam a ser mais consumidos pela internet, relacionando-os com a condição profissional e o nível de rendimentos. O estudo mostrou que, para a população estudante, de entre os vários tipos de produtos, desde supermercado, sistemas de áudio/ vídeo, componentes eletrônicos, entretenimento, saúde, viagens, desporto e vestuário, os produtos com maiores índices de compra on-line são as viagens 
que representavam 52,9\% e os sistemas de áudio/vídeo com 43,3\%. No caso da população não estudante, os produtos on-line mais consumidos são as viagens, com $60,8 \%$ e os sistemas áudio/vídeo, com $57,5 \%$. As intenções de compra para o futuro destes dois produtos aumentam em cerca de $40 \%$ para a população estudante e em cerca de $15 \%$ para a população não estudante.

Neste trabalho, conseguiu-se apurar que os inquiridos com idades compreendidas entre os 25 e 34 anos têm efetivamente mais transações de compras on-line, tendo $88,8 \%$ já comprado produtos pela internet. Relativamente à compra dos produtos turísticos consultados, este grupo têm a segunda maior percentagem dentro dos grupos de idade, isto é, 67,7\%, aceitando-se a hipótese H2 (Tabela 4 e 5).

Tabela 4. Compras on-line por grupos de idade

\begin{tabular}{|c|c|c|c|c|c|c|}
\hline \multirow{3}{*}{ Idades } & \multicolumn{4}{|c|}{ Compras on-line } & \multirow{3}{*}{$\mathbf{X}^{2}$} & \multirow{3}{*}{ Sig. } \\
\hline & \multicolumn{2}{|c|}{ Sim } & \multicolumn{2}{|c|}{ Não } & & \\
\hline & $\mathbf{N}$ & $\%$ & $\mathbf{N}$ & $\%$ & & \\
\hline Até 24 anos & 118 & 61,5 & 74 & 38,5 & \multirow{4}{*}{30,585} & \multirow{4}{*}{, $000^{\star}$} \\
\hline Entre 25 e 34 anos & 111 & 88,8 & 14 & 11,2 & & \\
\hline Entre 35 e 44 anos & 40 & 80,0 & 10 & 20,0 & & \\
\hline Mais de 45 anos & 20 & 76,9 & 6 & 23,1 & & \\
\hline
\end{tabular}

Fonte: Elaboração própria

Nota: ${ }^{*} p<0,05$

Em ambos os casos, compras genéricas pela internet e compras de produtos turísticos on-line, o $p$-value $=0,000<\alpha=0,05$ permite aceitar a hipótese de que existem diferenças no comportamento de compra on-line entre os quatro grupos de idade.

Tabela 5. Compra de produtos turísticos on-line por grupos de idade

\begin{tabular}{|c|c|c|c|c|c|c|}
\hline \multirow{3}{*}{ Idades } & \multicolumn{4}{|c|}{$\begin{array}{l}\text { Compra de produtos turísticos } \\
\text { On-line }\end{array}$} & \multirow{3}{*}{$\mathbf{X}^{2}$} & \multirow{3}{*}{ Sig. } \\
\hline & \multicolumn{2}{|c|}{ Sim } & \multicolumn{2}{|c|}{ Não } & & \\
\hline & $\mathbf{N}$ & $\%$ & $\mathbf{N}$ & $\%$ & & \\
\hline Até 24 anos & 83 & 44,1 & 105 & 55,9 & & \\
\hline Entre 25 e 34 anos & 84 & 67,7 & 40 & 32,3 & 20612 & non* \\
\hline Entre 35 e 44 anos & 26 & 52,0 & 24 & 48,0 & 20,045 & . \\
\hline Mais de 45 anos & 19 & 73,1 & 7 & 26,9 & & \\
\hline
\end{tabular}

Fonte: Elaboração própria

Nota: ${ }^{*} p<0,05$

Quanto à realização de compras pela internet quando comparadas por género, constata-se que é maior a percentagem de homens que o fazem, 
$82,2 \%$, enquanto a percentagem de mulheres é de 70,1\% (Tabela 7). O p-value $=0,012<\alpha=0,05$ permite aceitar, hipótese H3, a existência de diferenças no comportamento de compras on-line por género.

Tabela 6. Compras on-line por género

\begin{tabular}{|c|c|c|c|c|c|c|}
\hline \multirow{2}{*}{ Género } & \multicolumn{9}{c|}{ Sim } & Não & $\mathbf{X}^{\mathbf{2}}$ & Sig. \\
\hline Masculino & N & $\%$ & $\mathbf{N}$ & $\mathbf{\%}$ & & \\
Feminino & 97 & 82,2 & 21 & 17,8 & $\mathbf{6 , 2 6 5}$ & $\mathbf{0 1 2}^{\star}$ \\
\hline
\end{tabular}

Fonte: Elaboração própria

Nota: ${ }^{*} p<0,05$

\section{MOTIVAÇÕES PELA PROCURA DE FORNECEDORES TURÍSTICOS ON-LINE}

Avaliaram-se as motivações que levam os consumidores a recorrer a operadores turísticos on-line (Tabela 7). Os fatores mais valorizados são o preço baixo, com média de 4,16; a comodidade, com média de 4,14; e o produto atrativo, com média de 4,07. Já o fator menos valorizado, com uma média de 2,43, é o "Descrédito pelas agências de viagens em geral". Desta análise fica confirmada a valorização dada aos binómios preço/comodidade e acessibilidade/eficiência possibilitada pelos On-line Travel Agents.

Verificou-se a existência de diferenças estatisticamente significativas, entre os vários grupos etários, ao nível dos fatores motivacionais que levam os inquiridos a recorrer aos fornecedores turísticos on-line. Destacam-se os resultados obtidos em relação à comodidade, à falta de opções destes produtos nas agências de viagens e ao descrédito das agências de viagens em geral, sendo estes os únicos com $p$-value inferior a 0,05, levando assim à rejeição da hipótese $\mathbf{H 4}$. Os valores médios do fator preço são bastante idênticos entre todos os grupos de idade, sendo mais elevado entre as faixas mais novas, embora a diferença não seja significativa. Contudo, este é claramente o fator mais importante para a escolha do fornecedor on-line (média de 4,16). Os fatores comodidade $(4,29)$, produto atrativo $(4,15)$ e segurança do fornecedor on-line $(3,69)$ apresentam médias mais elevadas no grupo entre os 35-44 anos. 
Tabela 7. Motivações para recorrer a fornecedores turísticos on-line

\begin{tabular}{|c|c|c|c|c|c|c|c|c|}
\hline \multirow[b]{2}{*}{ Fator } & \multirow[b]{2}{*}{$\mathrm{N}$} & \multicolumn{5}{|c|}{$\%$} & \multirow{2}{*}{ Média } & \multirow{2}{*}{$\begin{array}{l}\text { Desvio } \\
\text { Padrão }\end{array}$} \\
\hline & & 1 & 2 & 3 & 4 & 5 & & \\
\hline Preço baixo & 274 & 1,5 & 1,8 & 11,3 & 49,6 & 35,8 & 4,16 (1) & 807 \\
\hline Comodidade & 273 & 4 & 2,2 & 9,9 & 58,2 & 29,3 & $4,14(2)$ & ,704 \\
\hline Segurança Operador On-line & 264 & 8 & 7,2 & 31,8 & 47,0 & 13,3 & 3,65 &, 828 \\
\hline Produto Atrativo & 269 &, 4 & 4 & 17,1 & 55,8 & 26,4 & $4,07(3)$ &, 692 \\
\hline $\begin{array}{c}\text { Não encontrou estas opções na Agência de } \\
\text { Viagens }\end{array}$ & 260 & 19,2 & 23,8 & 33,1 & 16,5 & 7,3 & 2,69 & 1,172 \\
\hline $\begin{array}{l}\text { Falta de tempo para consultar a sua Agência } \\
\text { de Viagens }\end{array}$ & 266 & 12,8 & 17,7 & 27,1 & 31,6 & 10,9 & 3,10 & 1,198 \\
\hline Descrédito nas Agências de Viagens em geral & 262 & 22,9 & 26,3 & 38,2 & 10,3 & 2,3 & 2,43 & 1,025 \\
\hline
\end{tabular}

Fonte: Elaboração própria

Nota: N - Casos Válidos; 1 - Discordo completamente; 2 - Discordo; 3 - Não concordo nem discordo; 4 - Concordo; 5 - Concordo completamente; Parêntesis - ranking dos três fatores mais valorizados.

Analisando os mesmos dados pelos níveis de rendimentos, constata-se que apenas as variáveis comodidade $(p$-value $=, 000)$ e descrédito nas agências de viagens em geral ( $p$-value $=0,025$ ) possuem valores inferiores $<\alpha=0,05$, levando a rejeitar a hipótese $\mathbf{H 5}$, de que existem diferenças estatisticamente significativas nestas motivações entre os vários níveis de rendimentos. Destaca-se o fator preço, que é mais valorizado pelos inquiridos com mais baixos rendimentos (média 4,28), embora estas diferenças não sejam estatisticamente significativas.

\section{MOTIVAÇÕES PELA PROCURA DE AGÊNCIAS DE VIAGENS}

Do resultado da análise à hipótese $\mathbf{H 6}$, pode-se concluir que os inquiridos com idades entre os 35 e 44 anos são os que mais procuram as agências de viagens tradicionais, com 57,9\%. O grupo de inquiridos com até 24 anos são os que menos recorrem, com 55,2\%. Contudo, o nível de significância $p$-value $=0,490>\alpha=0,05$ não permite aceitar a hipótese H6, uma vez que a procura pelas agências de viagens se revelou independente das faixas etárias.

Analisando a hipótese $\mathbf{H 7}$, conclui-se que os inquiridos com rendimentos até $500 €(52 \%)$ procuram mais agências de viagens tradicionais quando pretendem consultar algum produto ou serviço turístico. No entanto, o nível de significância $p$-value $=0,464>\alpha=0,05$ não permite aceitar a hipótese H7, 
uma vez que a procura pelas agências de viagens se apresentou independente dos níveis de rendimento.

Ahuja, Gupta e Raman (2003) investigaram o motivo dos consumidores não efetuarem compras através de fornecedores on-line. Concluíram que as barreiras com percentagens mais elevadas são a falta de privacidade e de segurança, assim como o facto de não existir um serviço de atenção ao cliente, seguidas da falta de interação (intermediação). Por sua vez, Heung e Zhu (2005) analisaram os critérios motivacionais para a escolha do consumidor pela agência de viagens, sendo que a credibilidade e a reputação foram identificadas como os atributos com maior percentagem. Evidencia-se a preocupação por critérios intangíveis, como a reputação da agência, a segurança e a qualidade do serviço prestado.

Na Tabela 8 apresenta-se a análise aos resultados obtidos nesse estudo referentes à motivação do consumidor quando recorre às agências de viagens tradicionais. Concluiu-se que, numa escala 5 de Likert, os inquiridos atribuem, predominantemente, classificação 4 (Concordo) em 8 dos 10 fatores: à confiança no produto oferecido pelas agências (média 3,83), à competência e ao profissionalismo da performance das agências (média 3,77), ao aconselhamento do destino turístico (média 3,78), ao apoio durante a viagem (média 3,62), ao prestígio da marca (média 3,60), ao relacionamento com o agente de viagens (média 3,51), à relação qualidade/preço (média 3,47 ) e à resolução de qualquer problema (média 3,24). Fica, de certa forma, salvaguardada a posição das agências de viagens tradicionais no mercado turístico, cujo binómio personalização/desmaterialização não é bem aceito pelo consumidor final.

Tabela 8. Motivações para recorrer às agências de viagens tradicionais

\begin{tabular}{c|c|c|c|c|c|c|c|c|} 
Fator & $\mathrm{N}$ & $\mathbf{9}$ & 2 & 3 & 4 & 5 & Média & $\begin{array}{c}\text { Desvio } \\
\text { Padrão }\end{array}$ \\
\hline Credibilidade / Prestígio da marca & 287 & 2,8 & 7,3 & 27,5 & 51,6 & 10,8 & 3,60 &, 878 \\
Confiança produto & 289 & 2,1 & 3,1 & 19,0 & 61,2 & 14,5 & $3,83(1)$ &, 788 \\
Relacionamento com Agente de Viagens & 290 & 3,4 & 10,0 & 31,7 & 41,4 & 13,4 & 3,51 &, 964 \\
Competência / Profissionalismo & 289 & 1,4 & 3,8 & 27,0 & 52,2 & 15,6 & $3,77(3)$ &, 807 \\
Relação qualidade/preço & 287 & 3,1 & 12,9 & 32,4 & 36,6 & 15,0 & 3,47 &, 999 \\
Possibilidade de Crédito & 285 & 18,6 & 22,1 & 36,1 & 18,9 & 4,2 & 2,68 & 1,107 \\
Aconselhamento do destino & 290 & 3,1 & 5,2 & 20,3 & 53,8 & 17,6 & $3,78(2)$ &, 904 \\
Não tem tempo a perder com internet & 285 & 33,3 & 34,4 & 22,5 & 6,0 & 3,5 & 2,11 & 1,058 \\
Resolvem qualquer problema & 286 & 6,3 & 15,4 & 35,0 & 35,0 & 8,4 & 3,24 & 1,019 \\
Apoio durante a viagem & 285 & 2,1 & 8,1 & 27,7 & 50,2 & 11,9 & 3,62 &, 875
\end{tabular}

Fonte: Elaboração própria 
Nota: N - Casos Válidos; 1 - Discordo completamente; 2 - Discordo; 3 - Não concordo nem discordo; 4 - Concordo; 5 - Concordo completamente; Parêntesis - ranking dos três fatores mais valorizados.

A marca de uma agência de viagens representa a combinação única das características do produto e dos valores associados a essa marca. É um compromisso de confiança com o cliente e o consumidor final. Uma marca forte constitui uma importante fonte de criação de valor. Uma marca forte simplifica a escolha do consumidor, reduz o risco de decisões de compra complexas e proporciona um benefício emocional adicional significativo (Schlesinger et al., 2009).

Face à situação atual de concorrência global, intensidade concorrencial, com produtos indiferenciados e facilidade de "substituição", a gestão de marcas assume-se como uma poderosa ferramenta de competitividade organizacional. A criação de valor para o cliente exige uma oferta de produtos e serviços inovadores e enriquecedores, capazes de excitar, deliciar e proporcionar experiências e prazeres inesperados. Por isso, a capacidade de inovação está intimamente associada à informação e ao conhecimento sobre os clientes. Este conhecimento é crítico para descobrir os valores pessoais principais, que orientam o comportamento dos consumidores e para definir os requisitos do produto e da marca.

Todos estes mecanismos de gestão são apenas possíveis com a colaboração estreita de ambos os intervenientes: fornecedor/cliente. Trata-se de estratégias para criação de novas fontes de valor, que as agências de viagens em geral devem adotar para subsistirem no mercado.

Nas motivações que os inquiridos casados mais valorizam, encontramse o aconselhamento no destino de férias (média 3,84), a competência e o profissionalismo (média 3,82), o relacionamento com o agente de viagens (média 3,81) e a resolução de qualquer problema (média 3,24). Este grupo de indivíduos procura segurança e credibilidade, solicita a ajuda de um profissional de turismo no aconselhamento do destino de férias (que muitas vezes são férias em família com os filhos), tendo a certeza de que terá o apoio necessário durante a viagem. 


\section{A INFLUÊNCIA DA CRISE NA ESCOLHA DO FORNECEDOR TURÍSTICO}

Outro objetivo deste estudo assenta na análise da influência da crise na escolha do fornecedor turístico. O sector do turismo tem todas as condições para ser um dos sectores cujas novas tendências na sociedade, economia e modelos empresariais terão maior impacto, obrigando a constantes transformações e readaptações dos modelos de negócios e dos processos organizacionais de gestão.

O turismo vive um momento complexo num contexto adverso. A atual conjuntura económica e financeira não permite ilusões. Trata-se de um quadro dramático em que as pesadas medidas governamentais afetam toda a economia, todas as empresas, o emprego, o nível de vida e a capacidade de consumo dos cidadãos. As atividades ligadas ao turismo ficam, assim, mais fragilizadas.

Por outro lado, o cliente é cada vez mais individualista, informado, exigente e sofisticado e está à procura de experiências cada vez mais personalizadas. Foi constatado que a internet é o canal mais utilizado para procurar informações sobre viagens e destinos, pois é o meio que reúne o maior número de fontes de informação, tanto de agências como informações locais acerca de tarifas aéreas, alojamento, cultura do país, entre outros. Esta informação torna-se crucial não só porque influencia, em grande parte, a seleção de um destino de férias, como também ajuda a preparar toda a viagem. A proliferação de tarifas aéreas internet only, os pacotes de férias vendidos on-line, assim como a penetração das companhias aéreas low cost, tornam o sector das viagens num dos maiores geradores de receitas para o e-commerce.

Numa análise geral aos resultados relativos à influência da crise na escolha do consumidor pelo fornecedor turístico on-line, este estudo permite concluir que efetivamente $57,2 \%$ dos inquiridos confirma que a atual crise económica influenciou a sua escolha.

Tabela 9. A influência da crise económica na escolha do fornecedor turístico 
Não

145

Total
$42,8 \%$

$100,0 \%$

Fonte: Elaboração própria

Nota: N - Casos Válidos

A análise destes resultados por faixas etárias permite verificar que a maior percentagem se reflete nos inquiridos até 24 anos de idade (65,1\%) (Tabela 10). Em contrapartida, o grupo de inquiridos com maior número de pessoas a afirmar que a atual crise económica não influenciou a escolha pelo fornecedor on-line situa-se na faixa com idades compreendidas entre os 35 e 44 anos, com $57,1 \%$. O valor registado no $p$-value $=0,038<\alpha=0,05$ possibilita concluir que não se rejeita a hipótese $\mathbf{H} \mathbf{8}$ de que a influência da crise na escolha do fornecedor on-line difere entre as faixas etárias.

Tabela 10. A influência da crise económica na escolha do fornecedor turístico por grupos de idade

Influência da crise na escolha do fornecedor

\begin{tabular}{|c|c|c|c|c|c|c|}
\hline \multirow[t]{2}{*}{ Idades } & \multicolumn{2}{|c|}{ Sim } & \multicolumn{2}{|c|}{ Não } & \multirow[t]{2}{*}{$X^{2}$} & \multirow[t]{2}{*}{ Sig. } \\
\hline & $\mathbf{N}$ & $\%$ & $\mathbf{N}$ & $\%$ & & \\
\hline Até 24 anos & 97 & 65,1 & 52 & 34,9 & \multirow{4}{*}{8,429} & \multirow{4}{*}{, $038 *$} \\
\hline Entre 25 e 34 anos & 67 & 57,8 & 49 & 42,2 & & \\
\hline Entre 35 e 44 anos & 18 & 42,9 & 24 & 57,1 & & \\
\hline Mais de 45 anos & 9 & 45,0 & 11 & 55,0 & & \\
\hline
\end{tabular}

Fonte: Elaboração própria

Nota: * $p<0,05$

Quanto à análise da hipótese $\mathbf{H 9}$ relativa à influência da crise na escolha do fornecedor turístico on-line por nível de rendimentos, o resultado obtido permite concluir que a maior percentagem se encontra nos inquiridos com rendimentos até $1.000 €(67,3 \%)$. E de facto, no grupo com rendimentos superiores a $2.500 €$, $55,0 \%$ afirma que a atual crise não influenciou a escolha pelo fornecedor on-line. Porém, o $p$-value $=0,060>\alpha=0,05$ não permite aceitar a hipótese $\mathbf{H 9}$ e, portanto, a influência da crise mostra-se idêntica entre os vários níveis de rendimento.

Relativamente à análise da hipótese $\mathbf{H 1 0}$ respeitante à influência da crise na escolha do fornecedor turístico on-line por estado civil, o resultado alcançado possibilitou verificar que são os inquiridos sozinhos que dizem mais ter influenciado, os solteiros com $60,6 \%$ e os divorciados com $66,7 \%$. Por outro lado, a percentagem de inquiridos casados é menor, com 50,0\%, no que diz respeito 
à influência da crise na escolha pelo fornecedor turístico on-line. Contudo, pelo $p$-value $=0,242>\alpha=0,05$ não se aceita a hipótese $\mathbf{H 1 0}$.

\section{CONCLUSÃO}

A crise que abalou as diferentes economias, acompanhada em muitos casos com pesadas medidas orçamentais e abrandamento do consumo, afeta todas as fontes de negócio. Com a recessão e o consequente downsizing nas empresas, o turismo é afetado bem como todas as atividades a montante e a jusante. Confirma-se uma fase de mudança e, com essa mudança, surgem ameaças e oportunidades ao se aperceber as novas exigências dos clientes, os seus interesses e os objetivos.

A internet implicou uma mudança de paradigma do negócio, com a consequente diminuição das margens ao longo do canal de distribuição, bem como elevados investimentos em tecnologia, levando ao desaparecimento de muitas agências que não tinham possibilidade de o fazer. Por outro lado, foi possível chegar mais rápida e eficazmente ao cliente final, eliminando custos e procedimentos desnecessários.

Outros fatores são invocados para a situação atual do sector, como o contexto económico e financeiro que, como verificado neste estudo, prejudica diretamente a procura dos consumidores pelas agências de viagens. Porém, percebem-se algumas diferenças no comportamento do consumidor quanto à consulta e à compra de produtos turísticos. Verifica-se que os fatores mais valorizados quando os consumidores recorrem a fornecedores on-line são o preço baixo, a comodidade e o produto atrativo. Já quando recorrem às agências de viagens, as motivações mais valorizadas são o prestígio da marca, a confiança no produto oferecido pelas agências, o relacionamento com o agente de viagens, a competência e o profissionalismo da performance, o aconselhamento do destino turístico e o apoio durante a viagem.

Os dados obtidos permitem traçar um perfil de cliente que recorre às agências de viagens: com idade entre os 35 e 44 anos, casado, com rendimento médio/ alto, com grau de escolaridade superior, valorizando sobretudo a credibilidade e prestígio da marca, a confiança no produto, o relacionamento com o agente 
de viagens, o profissionalismo e a competência, a relação qualidade/preço, não ter tempo a perder com a internet e o apoio durante a viagem.

O resultado dos dados nesta investigação permitiu confirmar que, de uma forma geral, a atual crise económica influenciou a escolha do consumidor por fornecedores on-line em detrimento das agências de viagens tradicionais. Contudo, este resultado é mais evidente em consumidores com baixos níveis de rendimento e com idades mais jovens. Na verdade, verifica-se que a crise influenciou a escolha do fornecedor turístico, concretamente, para 57,2\% dos inquiridos. Esta percentagem revelou-se mais elevada $(65,1 \%)$ nos inquiridos até 24 anos de idade. Quando se compararam os dados por nível de rendimentos, os inquiridos que auferem até $1.000 €$ têm maior percentagem $(67,3 \%)$ de respostas positivas. O grupo com rendimentos superiores a $2.500 €$ mostraramse menos afetados pela crise, com $55 \%$ dos inquiridos a afirmarem que a atual crise económica não influenciou a escolha pelo fornecedor turístico on-line.

Para concluir, só será possível a sobrevivência das agências de viagens tradicionais num mercado largamente fragmentado e ameaçado por uma concorrência feroz dos fornecedores turísticos on-line se investirem em inovação e desenvolvimento de soluções tecnológicas que melhorem a competitividade e otimizem os canais de distribuição, na possibilidade de se associarem a outros grupos do setor mais fortes, consolidando a marca, na formação dos recursos humanos, na gestão pelo relacionamento com os clientes e a criação de valor.

\section{REFERÊNCIAS BIBLIOGRÁFICAS}

AHUJA, M.; GUPTA, B.; RAMAN, P. An Empirical Investigation of Online Consumer Purchasing Behavior. Communications of the ACM, New York, Vol. 46, n.12, pp.145-151, December, 2003.

BARNETT, M.; STANDING C. Repositioning travel agencies on the Internet. Journal of Vacation Marketing, Vol. 7, n. 2, pp.143-150, April, 2001.

BÉDARD, F. Travel agencies in the era of e-commerce. Marketing Papers. Madrid: World Tourism Organization, 2002, pp.67-86.

BENNETT, M.M.; LAI, C.K. The impact of the internet on travel agencies in Tawain. Tourism and Hospitality Research, Vol. 6, n. 1, pp. 8-23, November, 2005. 
BUHALIS, D. Strategic Use of Information Technologies in the Tourism Industry. Tourism Management, Vol. 19, n. 5, pp. 409-421, October, 1998.

BUHALIS, D. Tourism and Information technologies: Past, Present and Future. Tourism Recreation Research, Vol. 25, n. 1, pp. 41-58, 2000.

BUHALIS, D.; LICATA, C. The future of eTourism intermediaries. Tourism Management, Vol. 23, n. 3, pp. 207-220, June, 2002.

BUHALIS, D.; O'CONNOR, P. Information Communication Technology Revolutionizing Tourism. Tourism Recreation Research, Vol. 30, n. 3, pp. 6-16, 2005.

DENCKER, A. Metodologia científica. In L. TRIGO (Org.), Turismo: como aprender, como ensinar. S. Paulo: Senac, 2001, pp. 257-283.

DUNFEE, T. W.; BLACK, B. M. Ethical Issues Confronting Travel Agents. Journal of Business Ethics, Kluwer Academic Publishers, Vol. 15, n. 2 pp. 207-217, February, 1996.

ELHAJ, M. Factors that contribute to consumers' perceptions of online and traditional travel reservation systems. Anatolia - An International Journal of Tourism and Hospitality Research. Vol. 23, n. 1, pp. 118-122, March, 2012.

FLORES, L.; CAVALCANTE, L.; RAYE, R. Marketing turístico: Estudo sobre o uso da tecnologia da informação e comunicação nas agências de viagens e turismo de Balneário Camboriú (SC, Brasil). Revista Brasileira de Pesquisa em Turismo, Vol. 6, n. 3, pp. 322-339, set./dez., 2012.

GALLARZA, M.G.; SAURAA, I.G. Value dimensions, perceived value, satisfaction and loyalty: an investigation of university students' travel behavior. Tourism Management, Vol. 27, n. 3, pp. 437-452, June, 2006.

GILBERT, D.; GAO, Y. (2005). A Failure of UK Travel Agencies to Strengthen Zones of Tolerance. Tourism and Hospitality Research, Vol. 5, n. 4, pp. 306-321, August, 2005.

HEUNG, V:; ZHU, P. Factors Affecting Choice of a Travel Agency for Domestic Tourism: The Case of Shanghai Residents in China. Journal of Travel \& Tourism Marketing, Vol.19, n. 4, pp. 13-24, 2005.

HOLLOWAY, C.; DAVIDSON, R.; HUMPHREYS, C. The business of tourism. $8^{\text {th }}$ edition. Canada: Pearson Education, 2009.

INKPEN, G. Information Technology for Travel and Tourism. Essex UK: Addison Wesley Longman, 1998.

KARAMI, M. Factors Influencing Adoption of Online Ticketing. Lulea University of Technology. Department of Business Administration and Social Sciences, Division of Industrial Marketing and E-commerce, 2006, pp. 1-84. 
LAW, R.; LEUNG, K.; WONG, J. The impact of the Internet on travel agencies. International Journal of Contemporany Hospitality Management, Vol. 6, n. 2, pp. 100-107, 2004.

LAWTON, L.; WEAVER, D. Travel Agency Threats and Opportunities: The Perspective of Successful Owners. International Journal of Hospitality \& Tourism Administration, Vol 10, n. 1, pp. 68-92, February, 2009.

LIN, H.F. Understanding Behavioral Intention to Participate in Virtual Communities. Cyberpsychology \& Behavior, Vol. 9, n. 5, pp. 540-547, October, 2006.

MARSILIO, M.; VIANNA, S. Agências de viagens e turismo e o impacto da internet: um estudo bibliométrico. Revista Turismo - Visão e Ação - Eletrônica, Vol. 16, n. 2, pp.450476, maio-agosto, 2014.

MARTINS, N. (17 maio 2015). O resgate em datas. Observador: 2015, maio 17, Especiais. Disponível em: http://observador.pt/especiais/o-resgate-em-datas/.

NIE, N.; ERBING, L. Internet use. California: Stanford Institute for the Quantitative Study of Society, pp.1-15, 2000.

O'CONNOR, P. (1999). Electronic Information Distribution in Tourism \& Hospitality. Oxford: $C A B, 1999$.

POON, A. Tourism, Technology and competitive strategies. Wallingford: $C A B$ International, pp. 130-136, January, 1993.

RENSBURG, M. Relevance of travel agencies in the digital age, African Journal of Hospitality, Tourism and Leisure, Vol. 3, n. 2, 2014.

RICHER, P.; O'NEILL-DUNNE, T. Distribution technology in the travel industry strategies for marketing success. London: Financial Times-Retail and Consumer, pp.1-16, 1999.

SARQUIS, A.; PIZZINATO, N.; GIULIANI, A.; PONTES, A. Estratégias de marketing: Estudo no setor de agências de viagens e turismo. Revista Brasileira de Pesquisa em Turismo, Vol. 9, n. 2, pp. 298-320, maio/ago, 2015.

SCHERTLER, W. Tourismus als Informationsgeschaft. Vienna: Ueberreuter, 1995.

SCHLESINGER, L. A.; VERHOEF, P.; LEMON, K.; PARASURAMAN, A.; ROGGEVEEN, A.; TSIROS, M. Customer Experience Creation: Determinants, Dynamics and Management Strategies. Journal of Retailing, Vol. 85, n. 1, pp. 31-41, March, 2009.

SHELDON, P. J. Tourism information technology. New York: Cab International, pp. 175-225, 1997.

STANDING, C.; TANG-TAYE, J-P.; BOYER, M. The Impact of the Internet in Travel and Tourism: A Research Review 2001-2010, Journal of Travel \& Tourism Marketing, Vol. 31, n. 1, pp. 82113, January, 2014. 
VUČETIĆ, A. (2012). Human Resources as a Competitive Advantage of Travel Agencies in Montenegro. Turizam, Vol. 16, n. 2, pp. 78-87.

WERTHNER, H. Information technology and tourism: a challenging relationship. Vienna: Springer Verlag, 1999.

XIANYUN GAO, T. (2013). Online vs. Traditional Travel Agency: What influence travel consumers' choices?. (Master's Thesis not published) Department of Service Management, Lund University, Sweden.

\section{CONTRIBUIÇÃO DOS AUTORES NA CONSTRUÇÃO DO ARTIGO}

VAREIRO: Organização da revisão de literatura, atualização da revisão, análise estatística, ajuda na interpretação de dados.

PINHEIRO: Revisão de literatura inicial, recolha de dados, inserção da base de dados, interpretação preliminar dos dados. 